\title{
Healthcare associated infections reports assessment in the neonatology and pediatrics departments
}

Evaluarea raportării cazurilor de infecţii asociate asistenţei medicale pe secţiile de neonatologie şi pediatrie

Elena MOCANU ${ }^{1}$, Corina VOINEA ${ }^{2}$, Valentin-Vasile BROASCĂ-MADAR ${ }^{1}$, Beatrice SEVERIN ${ }^{1}$, Liviu MERDINIAN ${ }^{1}$, Sorin RUGINĂ ${ }^{1,2,3,4}$

${ }^{1}$ Facultatea de Medicină, Universitatea „Ovidius“, Constanța, România

${ }^{2}$ Şcoala Doctorală de Medicină, Universitatea „Ovidius“, Constanța, România

${ }^{3}$ Academia de Ştiințe Medicale, România

${ }^{4}$ Academia Oamenilor de Ştiință din România

\begin{abstract}
Healthcare associated infections in pediatric patients are a major public health problem due to the fact that this category has a high infectious risk due to the body's high susceptibility to these infections.

This study aims to highlight that good reporting and management of these cases are essential in combating HAI by intensifying prevention measures and regular training of medical staff.

There was a significant increase in HAI reporting throughout the study period, especially among digestive and respiratory infections and sepsis.

The increase in the number of HAI cases represents is not a worsening of the situation in hospitals, but indicates an increase in the compliance of medical staff in terms of their identification and reporting, without accusatory meaning.
\end{abstract}

Keywords: healthcare associated infections, incidence, pediatric age

REZUMAT
Infecțiile asociate asistenței medicale la pacienții pediatrici reprezintă o problemă majoră a sistemului de
sănătate publică datorită faptului că această categorie are un risc infecțios ridicat prin receptivitatea mare a
organismului la aceste infecții.
Acest studiu îşi doreşte să scoată în evidență faptul că o bună raportare şi gestionare a acestor cazuri sunt
esențiale în combaterea IAAM prin intensificarea măsurilor de prevenție şi instruirea periodică a persona-
lului medical.
S-a constat o creştere semnificativă a raportării IAAM pe toată perioada studiată, in special în rândul
infecțiilor digestive, respiratorii şi sepsis.
Creştere a numărului de cazuri de infecții asociate asistenței medicale nu reprezintă o înrăutățire a situ-
ației din spitale, ci indică o creştere a complianței personalului medical în ceea ce priveşte identificarea şi
raportarea acestora, fără caracter acuzator.

Cuvinte cheie: infecții asociate actului medical, incidență, vârstă pediatrică 


\section{INTRODUCERE}

Secțiile de neonatologie și pediatrie au un risc infecțios major determinat de anumiți factori intrinseci (prematuritate, distrofie, suferințe respiratorii severe, cardiopatii congenitale), dar și de factori extrinseci (abord venos periferic, ventilație mecanică, reanimare profundă, durata crescută de spitalizare, posibila izolare defectuoasă a copiilor internați cu infecții comunitare, starea de sănătate a personalului de îngrijire) [1].

Receptivitatea organismului la infecții este o verigă determinantă a procesului epidemiologic al infecțiilor asociate actului medical (IAAM). Copiii nou-născuți și sugarii (in special prematurii, distroficii și cei alimentați artificial) reprezintă cea mai afectată și receptivă categorie de persoane, ei având o rezistență generală și locală scazută. Mecanismele imunologice sunt insuficient dezvoltate și posedă numeroase porți de intrare pentru germeni, slab apărate: mucoasa tractului respirator, intestinal, conjunctivele, tegumentele, ombilicul. Rezistența organismului este mult diminuată odată cu apariția unei suferințe care necesită internare, investigații și terapie complexă [2].

\section{MATERIAL ŞI METODĂ}

În cadrul acestei lucrări, am efectuat un studiu retrospectiv, analizând raportarea statistică a IAAM conform „Dării de seamă privind principalii indicatori ai cunoașterii sănătății - 10. Infecții interioare din spital" pentru perioada 01.01.2014-31.12.2018, în conformitate cu prevederile Ordinului Ministerului Sănătății nr. 919/2006 privind aprobarea normelor metodologice de înregistrare, stocare, prelucrare și transmitere a informațiilor legate de activitatea spitalului [3]. Datele necesare realizării acestui studiu au fost preluate din cadrul Direcției de Sănătate Publică Constanța și prelucrate în Microsoft Excel.

\section{REZULTATE}

În urma analizei descriptive a cazurilor de infecții asociate asistenței medicale înregistrate pe perioada celor 5 ani, 2014-2018, în unitățile sanitare cu paturi, pe secțiile de neonatologie și pediatrie, am observat o creștere semnificativă a numărului de cazuri raportate în fiecare an al studiului.
În anul 2014, raportarea cazurilor de infecții asociate asistenței medicale a fost extrem de mică, înregistrându-se un singur caz de septicemie pe secțiile de neonatologie și 1 caz de infecție respiratorie și 2 infecții digestive pe secțiile de pediatrie.

În 2015, numărul de infecții asociate asistenței medicale a fost ușor crescut, ajungând la un total de 17 cazuri, dintre care 3 cazuri au fost sepsis, 2 infecții respiratorii și 12 infecții digestive.

În anul 2016, se observă o creștere semnificativă a cazurilor de IAAM, datorită, probabil, unei mai bune raportari a acestora. Astfel, se ajunge la un număr total de 34 de infecții asociate asistenței medicale, iar tipul de infecții este mai variat decât în anii anteriori. Se înregistrează 2 infecții urinare, 2 infecții cutanate, 5 infecții respiratorii, 10 cazuri de sepsis și 15 infecții digestive.

Pentru anul 2017, s-a raportat un număr similar de IAAM cu cel raportat în anul anterior -un număr total de 32 infecții asociate actului medical, repartizate după cum urmează: 20 de infecții digestive, 7 cazuri de sepsis, 2 infecții respiratorii și 3 infecții cutanate.

Pe parcursul anului 2018, s-au înregistrat în total 44 cazuri, dintre care 8 de septicemie, 14 infecții digestive,

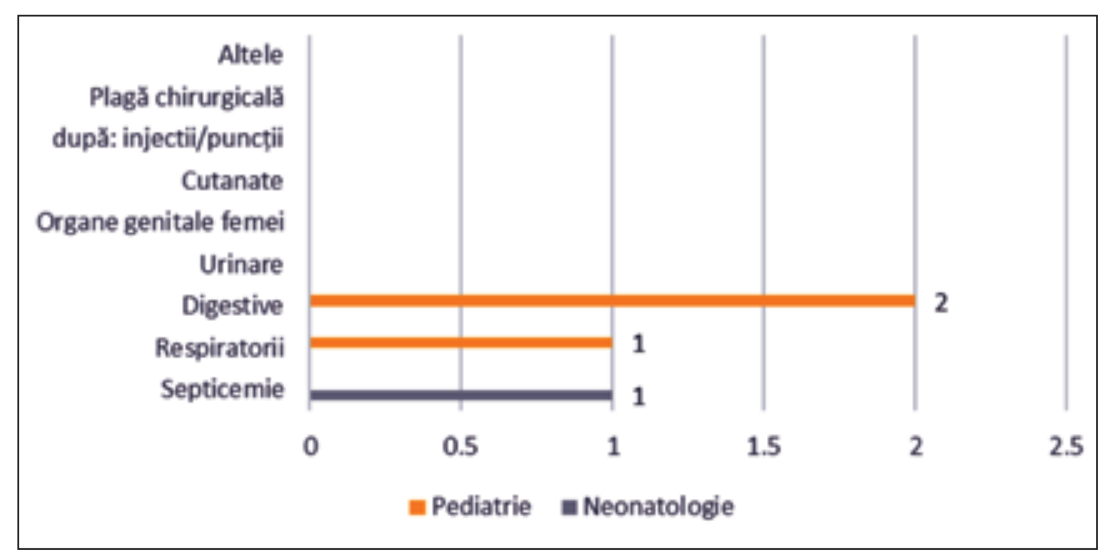

FIGURA 1. Distribuția cazurilor de IAAM pe secțiile de neonatologie și pediatrie în anul 2014

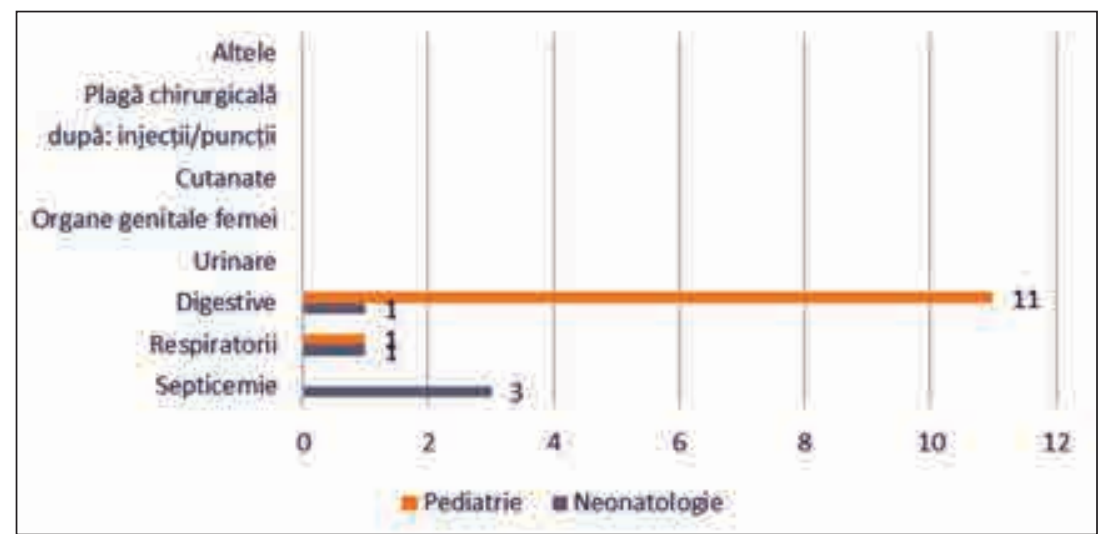

FIGURA 2. Distribuția cazurilor de IAAM pe secțiile de neonatologie şi pediatrie în anul 2015 


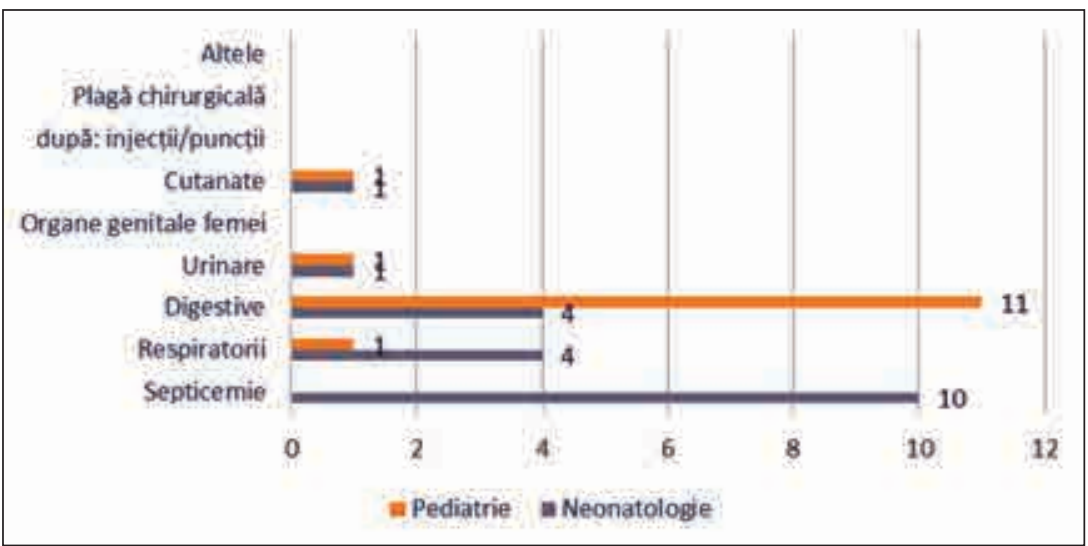

FIGURA 3. Distributia cazurilor de IAAM pe sectiile de neonatologie și pediatrie în anul 2016

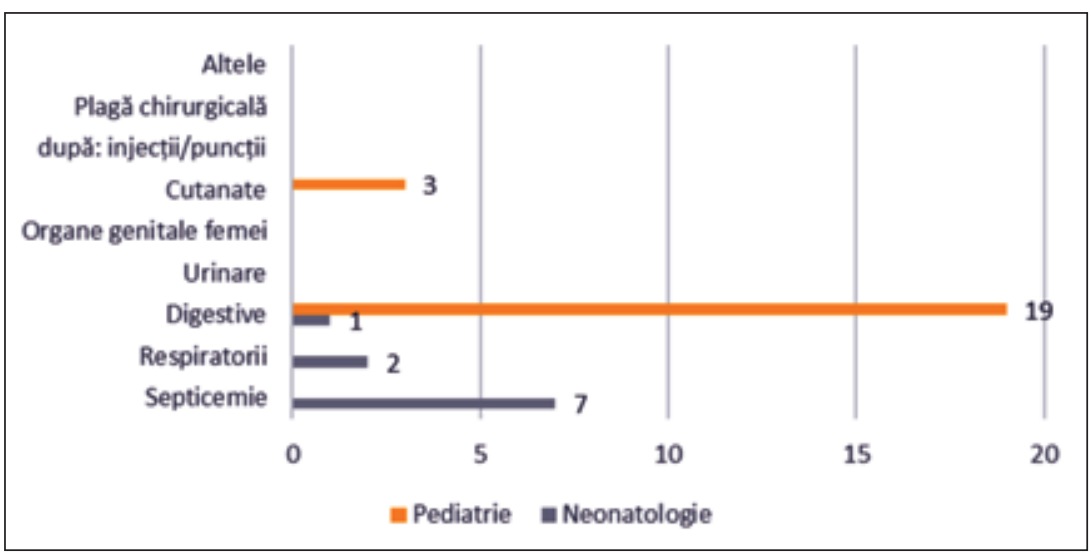

FIGURA 4. Distribuția cazurilor de IAAM în secțiile de neonatologie şi pediatrie în anul 2017

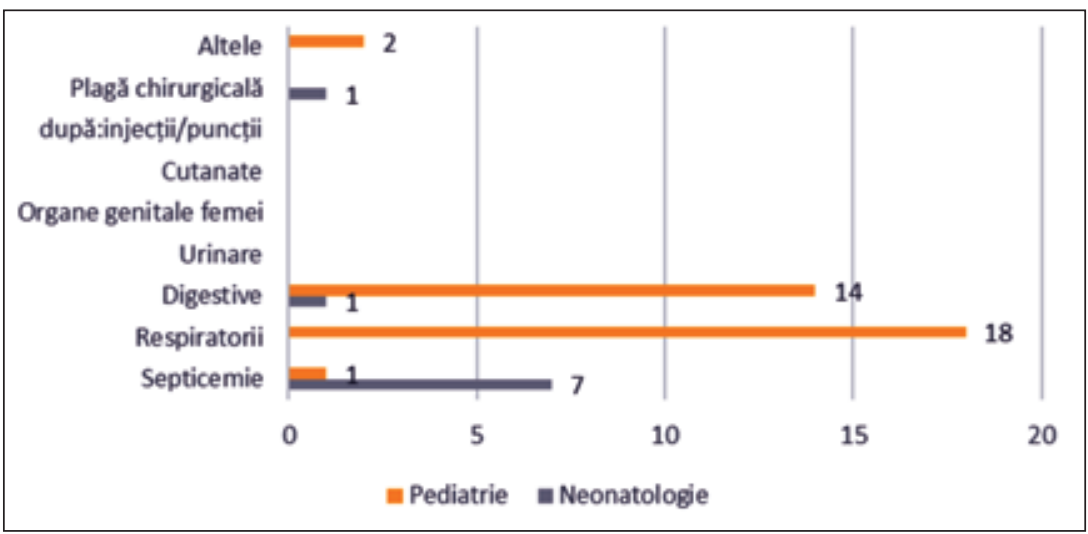

FIGURA 5. Distributtia cazurilor de IAAM în secțiile de neonatologie şi pediatrie în anul 2018

18 infecții respiratorii, 1 caz de infecție de plagă chirurgicală și alte 2 infecții cu localizare nespecificată.

Se poate observa că, din totalul infecțiilor asociate asistenței medicale analizate pe cei 5 ani, cele mai frecvente infecții au fost cele digestive ( 57 de cazuri pe secțiile de pediatrie și 7 cazuri pe secțiile de neonatologie), urmate de sepsis ( 28 de cazuri pe secțiile de neonatologie și 2 cazuri pe secțiile de pediatrie), infecțiile respiratorii (21 de cazuri pe secțiile de pediatrie și 7 cazuri pe secțiile de neonatologie), infecțiile cutanate ( 4 cazuri pe secțiile de pediatrie și 1 caz pe secțiile de neonatologie), infecțiile urinare (câte 1 caz pe fiecare secție), 1 caz de infecție de plagă chirurgicală pe secțiile de neonatologie și alte 2 infecții pe secțiile de pediatrie, fără a se preciza localizarea acestora.

\section{DISCUȚII}

Conform studiilor, incidența pentru infecțiile asociate asistenței medicale la copil este de $2-10 \%$, în funcție de unitatea spitalicească, cea mai mare rată de IAAM fiind înregistrată pe secțiile de terapie intensivă neonatală [4].

Modul de manifestare a acestor infecții poate fi sporadic sau epidemic. Vârsta de gestație și greutatea la naștere sunt cei mai importanți factori de risc pentru infecțiile nosocomiale, din cauza depresiei funcției sistemului imunitar [4].

La nivel global, un număr imens de pacienți pediatrici suferă de IAAM, cu rate de incidență cuprinse între $3,5 \%$ și $12 \%$ în țările dezvoltate și 5,7\% până la 19,1\% în țările cu venituri medii și mici. În țările în curs de dezvoltare, ratele IAAM în unitățile de terapie intensivă sunt de peste opt ori mai mari decât în Statele Unite ale Americii $[5,6]$.

Un studiu similar a fost realizat la Spitalul Clinic de Urgențe pentru Copii „Sf. Maria“ din Iași, pentru perioada 2012-2016, în urma căruia s-a observat că infecțiile respiratorii au fost cel mai des întâlnite (2014 - 34 de cazuri, 2015 - 29 de cazuri, 2016 - 47 de cazuri), urmate de infecțiile de plagă chirurgicală (2014 26 de cazuri, 2015 - 35 de cazuri, 2016 - 31 de cazuri), infecțiile de cateter (2014 - 26 de cazuri, 2015 - 14 cazuri, 2016 - 22 de cazuri), infecții cutanate (2014 - 15 cazuri, 2015 - 17 cazuri, 2016 - 33 de cazuri), infecții urinare (2014 - 16 cazuri, 2015 - 5 cazuri, 2016 - 17 cazuri), septicemii (2014 - 11 cazuri, 2015 - 7 cazuri, 2016 - 21 de cazuri), infecții digestive (2014 - 2 cazuri, 2015 - 1 caz, 2016 - 31 de cazuri), alte infecții (2014 - 2 
infecții, 2015 - 7 infecții, 2016 - 12 infecții) [7].

Într-un alt studiu, publicat în anul 2017, au fost analizate 17.273 de cazuri pediatrice din 29 de țări ale Uniunii Europene, evidențiindu-se 770 de infecții asociate actului medical apărute la 726 de copii și adolescenți [8].

\section{CONCLUZII}

Această creștere a numărului de cazuri de infecții asociate asistenței medicale nu reprezintă o înrăutățire a situației din spitale, ci se explică printr-o mai bună raportare și gestionare a cazurilor, în condițiile în care în spitale au fost organizate compartimente de prevenire a infecțiilor asociate îngrijirilor medicale. De asemenea, această creștere a numărului de cazuri raportate indică o creștere a complianței personalului medical în ceea ce privește identificarea și raportarea acestora, fără caracter acuzator.

Supravegherea continuă a infecțiilor asociate asistenței medicale este absolut necesară, facilitând obținerea informațiilor epidemiologice indispensabile pentru adoptarea și aplicarea unor măsuri în funcție de nivelul de risc infecțios înregistrat în cadrul unităților sanitare.

Conflict of interest: none declared Financial support: none declared

\section{$\overline{\text { BIBLIOGRAFIE }}$}

1. Rugină S. Infecţii nosocomiale, de la concepte la practică. Editura Muntenia, 2004.

2. Măgureanu E, Busuioc C. Ghid de epidemiologie practică. Profilaxia şi combaterea bolilor transmisibile. Editura Medicală, 1985;167-168.

3. Ordinul Ministerului Sănătăţii 919/2006 privind aprobarea normelor metodologice de înregistrare, stocare, prelucrare şi transmitere a informatiilor legate de activitatea spitalului.

4. Apetrei L. Infecţiile nosocomiale la copil, 2013. Available at: https://www.romedic.ro/ infectiile-nosocomiale-la-copil.

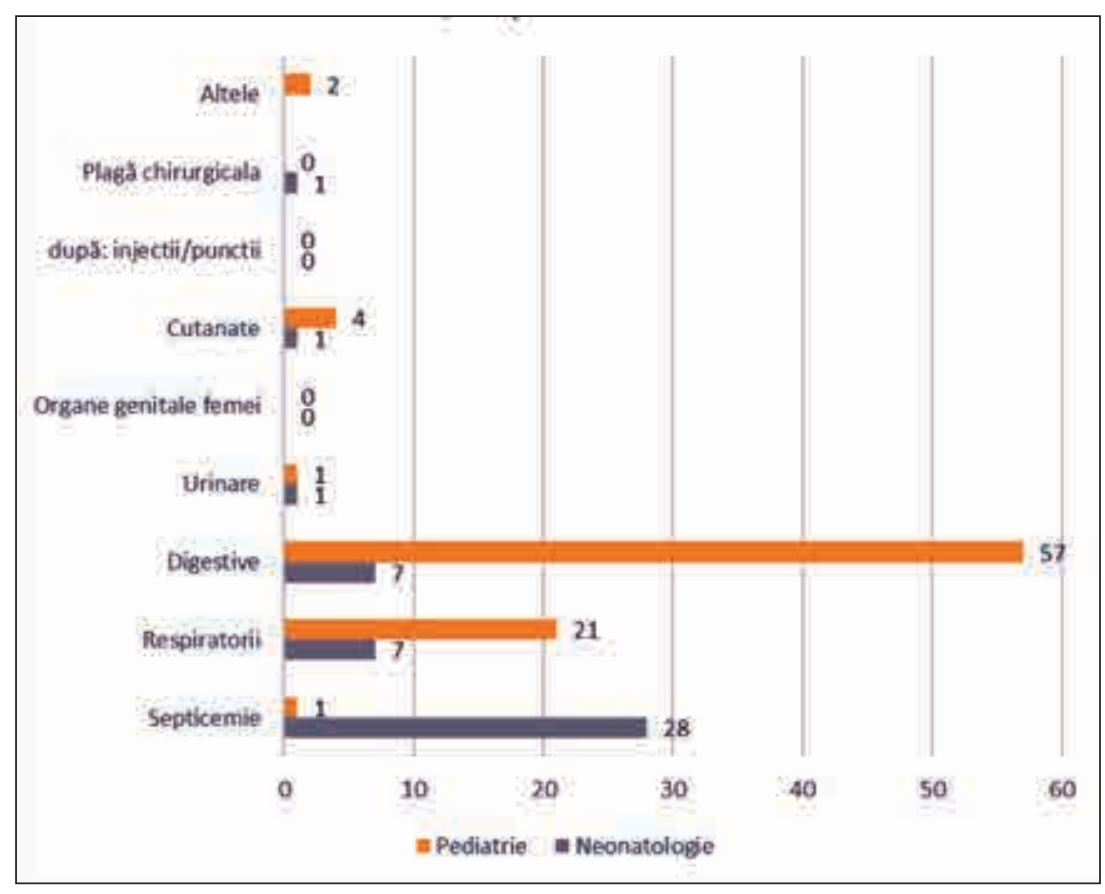

FIGURA 6. Distribuția cazurilor de IAAM în secțiile de neonatologie şi pediatrie în perioada 2014-2018

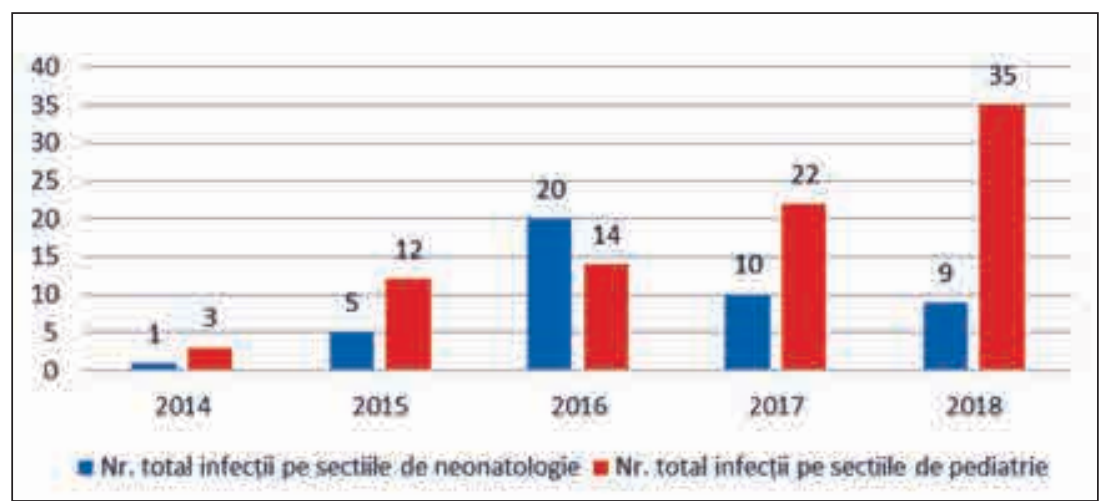

FIGURA 7. Numărul total de IAAM pe secțiile de neonatologie şi pediatrie în județul Constanța în perioada 2014-2018

5. Bagheri Nejad S, Allegranzi B, Syed SB, Ellis B, Pittet D. Health-care-associated infection in Africa: a systematic review. Bull World Health Organ. 2011;89(10):757-65.

6. Khazaei S, Adabi M, Bashirian S, Shojaeian M, Bathaei SJ, Karami M. Epidemiologic profile of nosocomial infections among paediatric patients in a referral hospital in Hamadan, west of Iran. New Microbes New Infect. 2020;38:100823.

7. Murgu A. Infecţiile asociate asistenţei medicale din punctul de vedere al managementului de vârf. Available at: https:// sanatateromania.ro/wp-content/
uploads/2017/05/09._IAAM_-Managementul_de_varf.pdf.

8. Zingg W, Hopkins S, Gayet-Ageron A, Holmes A, Sharland M, Suetens C; ECDC PPS study group. Health-care-associated infections in neonates, children, and adolescents: an analysis of paediatric data from the European Centre for Disease Prevention and Control point-prevalence survey. Lancet Infect Dis. 2017; 17(4):381-389. 